\title{
Lactobacillus plantarum subsp. argentoratensis subsp. nov., isolated from vegetable matrices
}

Correspondence

Franco Dellaglio

franco.dellaglio@univr.it

\section{Françoise Bringel, ${ }^{1}$ Anna Castioni, ${ }^{2}$ Daniel K. Olukoya, ${ }^{3}$ Giovanna E. Felis, ${ }^{2}$ Sandra Torriani ${ }^{2}$ and Franco Dellaglio ${ }^{2}$}

${ }^{1}$ Laboratoire de Dynamique, Evolution et Expression de Génomes de Microorganismes, Université Louis Pasteur/CNRS FRE 2326, 28 rue Goethe, 67083 Strasbourg, France

${ }^{2}$ Dipartimento Scientifico e Tecnologico, Facoltà di Scienze MM. FF. NN., Università degli Studi di Verona, Strada le Grazie 15, 37134 Verona, Italy

${ }^{3}$ Molecular Genetics \& Biotechnology unit, National Institute for Medical Research, Edmond Crescent, PMB 2013, Yaba, Lagos, Nigeria

Fourteen strains isolated from vegetable sources and identified as belonging to Lactobacillus plantarum presented an atypical pattern of amplification with a species-specific multiplex-PCR assay. Phylogenetic analysis of two protein-encoding genes, $\operatorname{rec} A$ (encoding the recombinase $\mathrm{A}$ protein) and cpn60 (encoding the GroEL chaperonin), as well as phenotypic and genomic traits revealed a homogeneous group of very closely related strains for which subspecies status is proposed, with the name Lactobacillus plantarum subsp. argentoratensis. The type strain is DKO $22^{\top}\left(=\operatorname{CIP} 108320^{\top}=\right.$ DSM $\left.16365^{\top}\right)$.
Lactobacillus plantarum belongs to the Lactobacillus caseiPediococcus phylogenetic group of the genus Lactobacillus (Hammes \& Vogel, 1995) and in particular to the L. plantarum phylogenetic subgroup (Hammes \& Hertel, 2003). This species is characterized by many metabolic activities that allow it to colonize different environments such as dairy products, pickled vegetables, fish products, silage, wine as well as mammal intestinal tracts (Vescovo et al., 1993). The species is highly heterogeneous (Dellaglio et al., 1975). Several studies, which have tried to elucidate intraspecific relationships, led to the description of two novel species: Lactobacillus pentosus and Lactobacillus paraplantarum (Zanoni et al., 1987; Curk et al., 1996). These three closely related species cannot be distinguished by $16 \mathrm{~S}$ rRNA gene sequence analysis because they show $99 \%$ sequence similarity. They also have very similar

Published online ahead of print on 14 March 2005 as DOI 10.1099/ ijs.0.63333-0.

Abbreviation: RAPD, randomly amplified polymorphic DNA.

The GenBank/EMBL/DDBJ accession numbers obtained in the present study are: $16 \mathrm{~S}$ rRNA gene sequence of $L$. plantarum subsp. argentoratensis DKO 22 ${ }^{\top}, \mathrm{AJ} 640078$; complete recA gene sequences of L. plantarum subsp. plantarum ATCC 14917 ${ }^{\top}$, AJ621668; L. plantarum subsp. argentoratensis DKO 22 ${ }^{\top}$, AJ640079; L. plantarum subsp. argentoratensis A7, AJ640080; L. pentosus LMG $10755^{\top}$, AJ621666; L. paraplantarum LMG 16673' ${ }^{\top}$ AJ621662; partial cpn60 gene sequences of $L$. plantarum subsp. argentoratensis DKO $22^{\top}$, AJ640081; L. plantarum subsp. plantarum ATCC $14917^{\top}$, AJ640082.

Positions of the primers of species-specific multiplex-PCR assay based on recA gene sequences are shown in a supplementary figure available in IJSEM Online. fermentation abilities: $L$. pentosus can be differentiated from L. plantarum only by its capacity to ferment glycerol and xylose (Zanoni et al., 1987). Some exceptions, however, exist: some $L$. plantarum strains are able to metabolize glycerol as with $L$. pentosus and not all $L$. pentosus strains can metabolize xylose (Bringel et al., 1996). Fermentation differences between $L$. plantarum and $L$. paraplantarum are even less helpful: the main difference is that strains of the latter species metabolize methyl $\alpha$-D-glucopyranoside, whereas $66 \%$ of L. plantarum strains cannot (Bringel et al., 1996).

With regard to molecular techniques, L. plantarum, $L$. pentosus and $L$. paraplantarum can be rapidly distinguished using PCR amplification targeting the 16S/23S rRNA gene spacer region (Berthier \& Ehrlich, 1998) or the recA gene as described by Torriani et al. (2001). Moreover, a polyphasic approach with a combination of RAPD (randomly amplified polymorphic DNA)-PCR, Southern hybridization and phenotypic traits not only distinguished the three species $L$. plantarum, $L$. paraplantarum and $L$. pentosus, but also revealed the presence of two groups of strains in the species L. plantarum (Bringel et al., 2001): $90 \%$ of these were closely linked to the L. plantarum type strain, ATCC $14917^{\mathrm{T}}$, and $10 \%$ (14 strains) formed a distinct group. We report here the analyses performed on those 14 'atypical' strains and, on the basis of collected data, a novel subspecies of L. plantarum is proposed.

The studied bacterial strains listed in Table 1 were grown in MRS at $37^{\circ} \mathrm{C}$. After genomic DNA extraction (Marmur, 1961), the recA-nested multiplex-PCR assay was performed as described by Torriani et al. (2001). This multiplex-PCR 


\section{Table 1. Strains tested}

ATCC, American Type Culture Collection, Manassas, VA, USA; CIP, Collection of bacterial strains of Institut Pasteur, Paris, France; CNRZ, Centre National de Recherches Zootechniques, INRA Jouy-en-Josas, France; LMG, BCCM/LMG Bacteria Collection, Laboratorium voor Microbiologie, Universiteit Gent, Belgium; NCFB, National Collection of Food Bacteria, Reading, UK; NCIMB, National Collection of Industrial and Marine Bacteria, Aberdeen, UK.

\begin{tabular}{|c|c|}
\hline Strain & Isolation source \\
\hline \multicolumn{2}{|c|}{ L. plantarum subsp. plantarum } \\
\hline ATCC $14917^{\mathrm{T}}$ & Pickled cabbage \\
\hline A12 & Cassava, Colombia \\
\hline ATCC 10012 & Unknown \\
\hline B41 & Silage, Italy \\
\hline CNRZ 1220 & Cheese, Egypt \\
\hline CNRZ 1246 & Domiati cheese, Egypt \\
\hline LAB R1M3 & Monte Veronese cheese, Italy \\
\hline LMF 415 & Silage \\
\hline LMG 18035 & Milk, Egypt \\
\hline NCFB 340 & Silage, UK \\
\hline NCIMB 8826 & Human saliva \\
\hline NS26 & Monte Veronese cheese, Italy \\
\hline ZW20 & Cheese, Switzerland \\
\hline 817 & Cheese, Italy \\
\hline 38AA & Cassava, Colombia \\
\hline \multicolumn{2}{|c|}{ L. plantarum subsp. argentoratensis } \\
\hline A1 & Cassava, Colombia \\
\hline DK 19 & White maize, Nigeria \\
\hline NCIMB 12120 & Fermented cereals (ogi), Nigeria \\
\hline 13 & Cow udder, Algeria \\
\hline 57.2 & Cassava, Colombia \\
\hline A4 & Cassava, Colombia \\
\hline A7 & Cassava, Colombia \\
\hline CNRZ 1889 & Fermented cereals (ogi), Nigeria \\
\hline CNRZ 1890 & Fermented millet (baba), Nigeria \\
\hline DKO $22^{\mathrm{T}}$ & Sour cassava, Nigeria \\
\hline DK 9 & Fermented cucumber, Nigeria \\
\hline DK 36 & Tapioca, Nigeria \\
\hline LP85-2 & Silage, France \\
\hline SF2A35B & Sour cassava, South America \\
\hline \multicolumn{2}{|c|}{ L. paraplantarum } \\
\hline LMG $16673^{\mathrm{T}}$ & Beer, France \\
\hline \multicolumn{2}{|l|}{ L. pentosus } \\
\hline LMG $10755^{\mathrm{T}}$ & Sawdust fermentation \\
\hline
\end{tabular}

assay uses a reverse primer (pRev) in combination with three species-specific forward primers (planF, pentF and paraF) to distinguish the closely related species of the L. plantarum group. Three species-specific amplification products of different length were obtained: $318 \mathrm{bp}$ for L. plantarum, $218 \mathrm{bp}$ for $L$. pentosus and $107 \mathrm{bp}$ for L. paraplantarum. The 14 atypical strains, isolated from vegetable sources, displayed an unexpected pattern characterized by two amplification bands, i.e. the 318 bp band typical of $L$. plantarum, and an additional $120 \mathrm{bp}$ band (see Fig. 1). To evaluate the origin and the specificity of this new band, further PCR amplifications were performed on the 14 strains and on L. plantarum ATCC $14917^{\mathrm{T}}$. Each of the three species-targeted forward primers was assayed in combination with the reverse primer pRev in separate PCR assays. As expected, a unique $318 \mathrm{bp}$ band was obtained when the primer specific for L. plantarum species was used. By contrast, in the presence of the primer pentF, specific for L. pentosus, a single amplification product of $120 \mathrm{bp}$ was obtained from all 14 strains (data not shown), but no amplification was detected with the type strain of L. plantarum. Sequencing confirmed that both amplicons are $r e c A$ gene fragments. Moreover, the $r e c A$ gene sequences of the 14 strains were more similar to the recA gene of L. plantarum ATCC $14917^{\mathrm{T}}$, confirming that they belong to the species $L$. plantarum. The positions of the multiplexPCR primers on the recA gene sequence of $L$. plantarum ATCC $14917^{\mathrm{T}}$ (GenBank accession no. AJ621668), L. plantarum DKO $22^{\mathrm{T}}$ (AJ640079), L. pentosus LMG $10755^{\mathrm{T}}$ (AJ621666) and L. paraplantarum LMG 16673 ${ }^{\mathrm{T}}$ (AJ621662) are given in Supplementary Fig. S1 available in IJSEM Online.

The 14 atypical $L$. plantarum strains were also compared by using physiological tests to a panel of $15 \mathrm{~L}$. plantarum strains, including L. plantarum ATCC $14917^{\mathrm{T}}$, and to the type strains of $L$. paraplantarum and $L$. pentosus. Table 2 lists the fermentation abilities of the 14 strains evaluated using the API-50 CHL detection kit as described by the manufacturer (bioMérieux). All the L. plantarum strains and the type strains of $L$. pentosus and $L$. paraplantarum fermented galactose, D-glucose, D-fructose, D-mannose, mannitol, $\mathrm{N}$ acetylglucosamine, amygdalin, aesculin, salicin, cellobiose, maltose, sucrose and $\beta$-gentiobiose. None of the strains was able to ferment L-sorbitol, inulin, D-lyxose, erythritol, D-arabinose, L-xylose, adonitol, methyl $\beta$-xyloside, inositol, D-tagatose, DL-fucose, L-arabitol, 2-ketogluconate or 5ketogluconate. By contrast, different fermentation trends were observed between the two groups of $L$. plantarum strains for five carbohydrates (Table 2). All strains were negative for catalase activity (Freney et al., 1999). Growth at $15^{\circ} \mathrm{C}$ (positive) and $45^{\circ} \mathrm{C}$ (negative) was tested in MRS broth. Hydrolysis of arginine determined according to the method described by Sharpe (1979) was not positive for any strain. Lactic acid isomers were assayed enzymically using the DL-lactate test kit (Boehringer) after growth in MRS. The 14 atypical $L$. plantarum strains formed both isomers, with the $\mathrm{D}$ isomer accounting for $65-70 \%$ of the total lactic acid produced.

The partial 16S rRNA gene sequence was determined from strain DKO $22^{\mathrm{T}}$, one of the 14 atypical L. plantarum strains, using primers Lac16S-for (5'-AATGAGAGTTTGATCCTGGCT- $3^{\prime}$ ) and Lac16S-rev (5'-GAGGTGATCCAGCCGCAGGTT- $\left.3^{\prime}\right)$. The reaction mixture $(20 \mu \mathrm{l})$ contained $30 \mathrm{ng}$ template DNA, $1.5 \mathrm{mM} \mathrm{MgCl}_{2}, 0.2 \mathrm{mM}$ dNTPs, $1 \mu \mathrm{M}$ each primer and $1 \mathrm{U}$ Taq DNA polymerase (Polymed) 


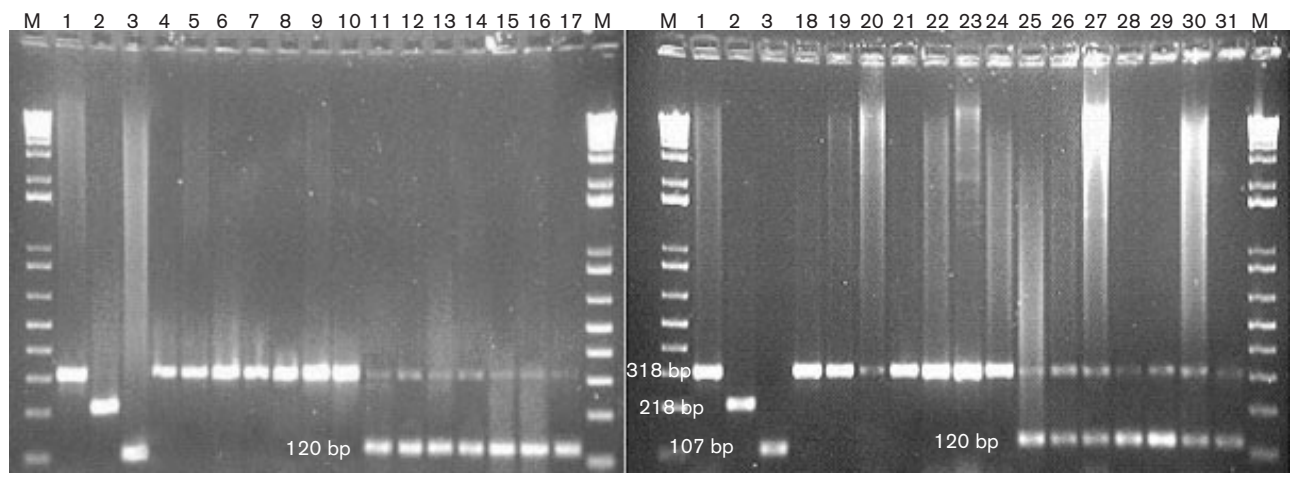

Fig. 1. Multiplex-PCR amplification patterns. Lanes: $M$, marker 1 kb plus DNA ladder; 1 , L. plantarum ATCC $14917^{\top} ; 2, L$. pentosus LMG $10755^{\top}$; 3, L. paraplantarum LMG $16673^{\top} ; 4-31$, L. plantarum NCFB 340, B41, CNRZ 1246, 38AA, CNRZ 1220, A12, NCIMB 8826, CNRZ 1889, CNRZ 1890, DKO 22 ${ }^{\top}$, DK 9, DK 36, LP85-2, SF2A35B, LMG 18035, LAB R1M3, ZW20, NS26, LMF 415, 817, ATCC 10012, A1, DK 19, NCIMB 12120, 13, 57.2, A4 and A7.

in a standard reaction buffer. After an initial denaturation of 4 min at $94{ }^{\circ} \mathrm{C}, 25$ cycles of $1 \mathrm{~min}$ at $94^{\circ} \mathrm{C}, 1.5 \mathrm{~min}$ at $50^{\circ} \mathrm{C}$, 2 min at $72{ }^{\circ} \mathrm{C}$ and a final extension at $72^{\circ} \mathrm{C}$ for 7 min were performed. The $1.6 \mathrm{~kb}$ amplification product was extracted from agarose gel (Promega elution kit) and sequenced at the Biomolecular Research (BMR) Center at Padua University (Italy). The sequence obtained was aligned with the $16 \mathrm{~S}$ rRNA gene sequences of other Lactobacillus species using the CLUSTAL_X program (Thompson et al., 1997). Phylogenetic analysis was performed with the MEGA version 2.1 program (Kumar et al., 2001): the distance matrix was obtained with Tamura's three-parameter model and tree reconstruction was obtained with minimum evolution clustering. An analysis of the robustness of the tree was obtained by using a bootstrap approach with 1000 replicates. A maximumparsimony method was also applied with default options. Maximum-likelihood analysis was performed with the DNAML program in the PHYLIP software package. Very low divergence of sequences (similarity of $99 \%$ ) in the phylogenetic trees confirmed strongly that strain DKO $22^{\mathrm{T}}$ belongs to the $L$. plantarum group (data not shown). Sequence analysis of the $16 \mathrm{~S}$ rRNA gene did not allow us to distinguish very closely related species whereas proteinencoding genes did (Torriani et al., 2001). Therefore, the complete recA gene sequences of selected $L$. plantarum strains (ATCC $14917^{\mathrm{T}}, \mathrm{DKO} 22^{\mathrm{T}}, \mathrm{A7}$ ) and of the L. pentosus

Table 2. Fermentation activities of the 14 atypical Lactobacillus plantarum strains and their incidence (percentage values) in the two groups of $L$. plantarum strains

\begin{tabular}{|c|c|c|c|c|c|}
\hline Strain & Dulcitol & Melezitose & Methyl $\alpha$-D-mannoside & L-Arabinose & D-Turanose \\
\hline A1 & + & - & - & - & - \\
\hline DK 19 & + & - & - & - & - \\
\hline NCIMB 12120 & - & - & - & + & - \\
\hline 13 & - & - & - & - & + \\
\hline 57.2 & + & - & - & - & - \\
\hline A4 & + & - & - & - & - \\
\hline A7 & + & - & - & - & - \\
\hline CNRZ 1889 & - & - & - & + & + \\
\hline CNRZ 1890 & - & - & - & + & + \\
\hline DKO $22^{\mathrm{T}}$ & - & - & - & - & - \\
\hline DK 9 & - & - & - & - & - \\
\hline DK 36 & - & - & - & - & - \\
\hline LP85-2 & - & - & - & - & + \\
\hline SF2A35B & + & - & - & - & - \\
\hline $\begin{array}{l}\text { Fermentation abilities of the } 14 \text { atypical } \\
\text { L. plantarum strains }\end{array}$ & $+(43 \%)$ & $-(100 \%)$ & $-(100 \%)$ & $-(79 \%)$ & $-(71 \%)$ \\
\hline $\begin{array}{l}\text { Fermentation abilities of ATCC } 14917^{\mathrm{T}} \\
\text { and the other } L \text {. plantarum strains } \\
\text { tested (14 strains) }\end{array}$ & $-(100 \%)$ & $+(63 \%)$ & $+(69 \%)$ & $+(63 \%)$ & $+(63 \%)$ \\
\hline
\end{tabular}


and L. paraplantarum type strains were obtained. The corresponding $r e c A$ genes were PCR-amplified using primers annealing the flanking gene sequences, which were conserved in the sequenced genomes (http://www.tigr.org) of bacteria belonging to the phylum Firmicutes (data not shown). The upstream $\operatorname{cinA}$ gene (accession no. NT01LP2031 in L. plantarum WCFS1, according to TIGR annotation) encodes a putative competence-damage protein. The downstream gene (accession no. NT01LP2029 in L. plantarum WCFS1, according to TIGR annotation) encodes a conserved protein with unknown function. The recA-flanking gene sequences were used to design degenerate primers to amplify two overlapping fragments that included $r e c A$. A $1.4 \mathrm{~kb}$ fragment corresponding to the $5^{\prime}$-region was amplified with degenerate primers cinA-f (5'-CGAGTTTTGCGGTTTTGTGGNATHGGNGA- $3^{\prime}$ ) and AN-r (5'-CRATTTTTTCACGRATYTG- $\left.{ }^{\prime}\right)$. The reaction mixture contained $300 \mathrm{ng}$ DNA template, $2 \mathrm{mM} \mathrm{MgCl}_{2}$, $0.2 \mathrm{mM}$ dNTPs, $1 \mu \mathrm{M}$ each primer and $2.5 \mathrm{U}$ Taq DNA polymerase (Sigma) in a standard reaction buffer. After an initial denaturation of $5 \mathrm{~min}$ at $94^{\circ} \mathrm{C}, 30$ cycles of $1 \mathrm{~min}$ at $94{ }^{\circ} \mathrm{C}, 1.5 \mathrm{~min}$ at $44^{\circ} \mathrm{C}, 1.5 \mathrm{~min}$ at $72^{\circ} \mathrm{C}$ and a final extension at $72{ }^{\circ} \mathrm{C}$ for $5 \mathrm{~min}$ were performed. The $1 \cdot 1 \mathrm{~kb} 33^{\prime}$-end fragment was amplified using AN-f (5'-AAATYGAWGGNGARATGGG-3') and HDIG-r (5' -TGTTCACGAAAAATTTGATTTTCTTCYTTNGCYTC$\left.3^{\prime}\right)$. Reaction mixtures contained 300 ng DNA template, $2 \mathrm{mM} \mathrm{MgCl}, 0.1 \mathrm{mM}$ dNTPs, $0.5 \mu \mathrm{M}$ each primer and 1.5 U Taq DNA polymerase (Sigma) in a standard reaction buffer. Reaction conditions were the same as those described above, except primer annealing was performed at $42{ }^{\circ} \mathrm{C}$ rather than $44{ }^{\circ} \mathrm{C}$. The amplified fragments from $L$. plantarum DKO $22^{\mathrm{T}}$, A7 and ATCC $14917^{\mathrm{T}}$, L. pentosus LMG $10755^{\mathrm{T}}$ and L. paraplantarum LMG $16673^{\mathrm{T}}$ were sequenced. The recA gene sequence of $L$. plantarum WCFS1, available in the EMBL database (GenBank/EMBL accession no. AL935258), was retrieved from its complete genome sequence (Kleerebezem et al., 2003). The sequenced strain WCFS1 is isogenic to strain NCIMB 8826, which was included in the present study (Table 1) and gave a single 318 bp multiplex-PCR assay amplification product as obtained with the L. plantarum type strain (see Fig. 1). The recA gene was longer in L. plantarum (1143 bp) than in L. pentosus and in L. paraplantarum (both $1137 \mathrm{bp}$ ). Alignments of the L. plantarum recA nucleotide sequences revealed $100 \%$ similarity between strains DKO $22^{\mathrm{T}}$ and $\mathrm{A} 7$, $99 \cdot 7 \%$ similarity between strains ATCC $14917^{\mathrm{T}}$ and WCFS1, but only $93 \%$ similarity between the two L. plantarum recA gene clusters (strains DKO $22^{\mathrm{T}} / \mathrm{A} 7$ versus ATCC $\left.14917^{\mathrm{T}} / \mathrm{WCFS} 1\right)$. L. plantarum strains shared about $81-$ $82 \%$ sequence similarity with $L$. pentosus and L. paraplantarum when similarity values were calculated on matching positions in L. pentosus and L. paraplantarum $1134 \mathrm{bp}$ recA genes (without the stop codon). Thus, recA gene sequence analysis not only clearly distinguished between L. plantarum, L. paraplantarum and L. pentosus, but also identified two separate groups within the L. plantarum species. A phylogenetic tree based on the complete

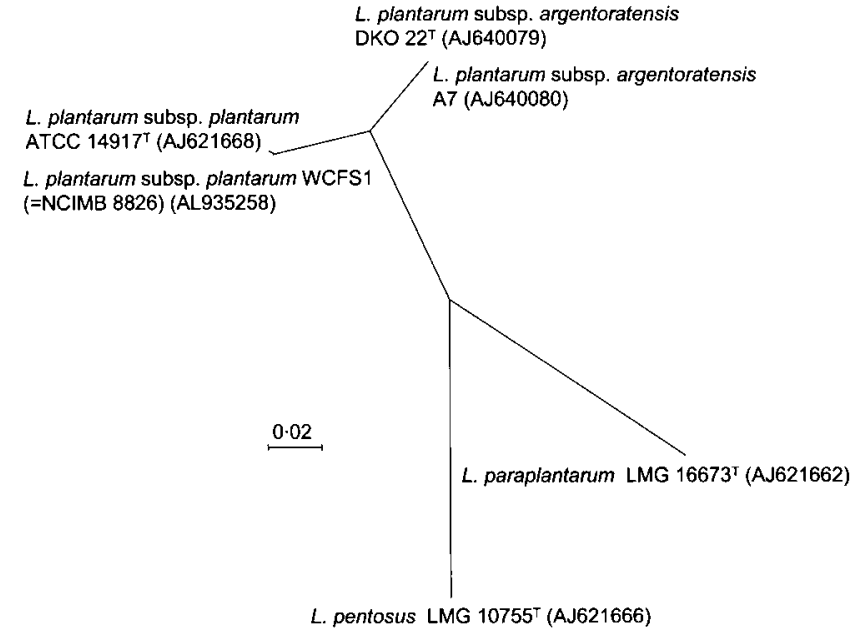

Fig. 2. Phylogenetic tree based on recA gene sequence analysis showing the phylogenetic relationship of $L$. plantarum subsp. argentoratensis subsp. nov. with other strains of $L$. plantarum subsp. plantarum, L. pentosus and L. paraplantarum. The distance matrix was calculated with Tamura's three-parameter formula and the tree was inferred by minimum evolution (MEGA2 software; Kumar et al., 2001). Bootstrap values at the nodes were all $100 \%$ and were calculated on 1000 resamplings. Maximum-parsimony and maximum-likelihood analyses gave almost identical results. Bar, 0.02 substitutions per nucleotide position.

recA gene sequences was obtained as described above and is shown in Fig. 2. The two L. plantarum clusters deduced from the complete sequence analysis of $\operatorname{rec} A$ genes in four strains was validated in the other $L$. plantarum strains by comparing a $750 \mathrm{bp}$ internal recA sequence obtained as described by Dellaglio et al. (2004). About 20 ng PCR product was restricted with endonucleases $A f a \mathrm{I}, B a m \mathrm{HI}$ and SalI (Takara; $5 \mathrm{U}, 1 \mathrm{~h}$ ). The same restriction patterns found in L. plantarum DKO $22^{\mathrm{T}}$ were found in 12 of the 14 atypical strains (data not shown). The two exceptions, strains DK 19 and SF2A35B, showed the same restriction pattern as for L. plantarum ATCC $14917^{\mathrm{T}}$, suggesting sequence divergence in their restriction enzyme recognition sites.

Strains from the two L. plantarum groups can be distinguished by the size of the products obtained with a recAnested multiplex-PCR assay and in particular by the amplification product obtained using primer set pentF/ pRev (see above and Fig. 1). In DKO $22^{\mathrm{T}}$, a $\mathrm{C} \rightarrow \mathrm{T}$ point mutation in the recA sequence (nucleotide 505 in GenBank accession number AJ640079) was linked to the specific annealing of primer pentF. The same point mutation was also found in strain A7 but not in L. plantarum ATCC $14917^{\mathrm{T}}$ and WCFS1 (see Supplementary Fig. S1). Thus, in the recA-nested multiplex-PCR test, the two L. plantarum groups can be discriminated on the basis of a $\mathrm{C} \rightarrow \mathrm{T}$ sequence divergence. 
Comparative sequence analysis on a second proteinencoding gene, cpn60, was also performed. Part of the cpn60 gene was amplified using the degenerate primers cpn- $\mathrm{f}$ (5'-CTTGGGCCCAAAAGGCMGNAAYGTNGT- $3^{\prime}$ ) and cpn-r (5'-CCAACCGTTCTTGCAATTTTTCNCKRTCRAA-3'). The reaction mixture $(20 \mu \mathrm{l})$ contained $100 \mathrm{ng}$ template DNA, $2 \mathrm{mM} \mathrm{MgCl} 2,0 \cdot 1 \mathrm{mM}$ dNTPs, $1 \mu \mathrm{M}$ of each primer and $1.5 \mathrm{U} \mathrm{Taq}$ polymerase in a standard reaction buffer. After an initial denaturation of $5 \mathrm{~min}$ at $94{ }^{\circ} \mathrm{C}, 30$ cycles of $1 \mathrm{~min}$ at $94{ }^{\circ} \mathrm{C}, 1 \mathrm{~min}$ at $55^{\circ} \mathrm{C}, 1.5 \mathrm{~min}$ at $72{ }^{\circ} \mathrm{C}$ and a final extension at $72{ }^{\circ} \mathrm{C}$ for $7 \mathrm{~min}$ were performed. Amplicons of the expected length of about $1.0 \mathrm{~kb}$ were obtained for all the strains. Amplification products of about $450 \mathrm{bp}$ were sequenced for both $L$. plantarum DKO $22^{\mathrm{T}}$ and ATCC $14917^{\mathrm{T}}$. The two groups of L. plantarum could not be distinguished with cpn60 partial sequence analysis as their sequences were highly similar $(99 \cdot 8 \%)$.

In conclusion, the 14 atypical strains belonged to L. plantarum as previously determined with Southern blot analysis with species-specific probes and RAPD-PCR (Bringel et al., 2001), with DNA-DNA hybridization of LP85-2 with the type strain of L. plantarum (Bringel et al., 1996) and with multiplex-PCR assay. However, for five carbohydrates, these 14 strains had different fermentation trends from those of the other L. plantarum strains tested (Table 2). Moreover, the 14 strains were easily distinguished based on highly standardized, reproducible and independent molecular tests, such as Southern analysis (Bringel et al., 1996), RAPD-PCR analysis (Bringel et al., 2001), recA multiplexPCR assay (Torriani et al., 2001) and recA gene sequence analysis. Moreover, comparative analysis of 20 strains of $L$. plantarum using microarrays genotyped $L$. plantarum strains into two clearly distinguishable groups in agreement with the results of this study (unpublished data; personal communication of D. Molenaar, F. Bringel, F. Schuren, W. de Vos, R. Siezen and M. Kleerebezem). These results justify a novel subspecies designation for the 14 atypical strains in the species L. plantarum, for which the name Lactobacillus plantarum subsp. argentoratensis subsp. nov. is proposed. According to Rule 40b of the Bacteriological Code (Lapage et al., 1992), the description of a new subspecies automatically creates the subspecies $L$. plantarum subsp. plantarum, which contains the type strain (ATCC $14917^{\mathrm{T}}$ ).

\section{Description of Lactobacillus plantarum subsp. plantarum subsp. nov.}

Lactobacillus plantarum subsp. plantarum (plan.ta'rum. L. fem. n. planta a sprout; M.L. n. planta a plant; M.L. gen. pl. n. plantarum of plants).

Gram-positive, non-motile, non-spore-forming straight rods with rounded ends, usually $0 \cdot 9-1 \cdot 2 \mu \mathrm{m}$ by $3-8 \mu \mathrm{m}$, that occur singly, in pairs or in short chains. Facultatively anaerobic; growth occurs at $15{ }^{\circ} \mathrm{C}$ but not at $45^{\circ} \mathrm{C}$. Both isomers of lactic acid are produced. Gas from glucose is not produced. Catalase is not produced, but some strains may exhibit pseudocatalase activity especially if grown under glucose limitation. Amygdalin, cellobiose, aesculin, Dfructose, galactose, $\beta$-gentiobiose, $N$-acetylglucosamine, $\mathrm{D}$ glucose, lactose, maltose, mannitol, D-mannose, melibiose, trehalose, salicin and sucrose are fermented. Adonitol, Darabinose, L-arabitol, erythritol, DL-fucose, 5-ketogluconate, methyl $\beta$-xylose, 2-ketogluconate, inositol, inulin, D-lyxose, L-sorbitol, D-tagatose and DL-xylose are not fermented. Arginine is not deaminated. meso-Diaminopimelic acid is present in the cell wall and ribitol or glycerol have been described to be present as teichoic acids. G+C content of the DNA is $44-46$ mol\%. Considering phylogenetic placement based on $16 \mathrm{~S}$ rRNA gene sequence analysis, $L$. plantarum belongs to the $L$. plantarum phylogenetic subgroup (Hammes \& Hertel, 2003), very closely related to $L$. paraplantarum and L. pentosus. The three species are easily distinguishable by means of molecular techniques: Southern hybridization with a pyr probe on BglI digestion of chromosomal DNA (Bringel et al., 1996, 2001), multiplex species-specific PCR analysis (Torriani et al., 2001) and recA gene sequencing. Such techniques also allow the differentiation of the two subspecies of $L$. plantarum, L. plantarum subsp. plantarum and L. plantarum subsp. argentoratensis. When analysed by a specific multiplex-PCR approach (Torriani et al., 2001), DNA of strains belonging to $L$. plantarum subsp. plantarum produce a single amplification product of $318 \mathrm{bp}$. A rough separation of the two subspecies of L. plantarum may also be obtained based on fermentation profiles of dulcitol, melezitose, methyl $\alpha$-Dmannoside, L-arabinose, D-turanose (Table 2): usually, $L$. plantarum subsp. plantarum strains do not ferment dulcitol but do metabolize melezitose, methyl $\alpha$-D-mannoside, L-arabinose and D-turanose.

The type strain is ATCC $14917^{\mathrm{T}}\left(=\mathrm{NCDO} 1752^{\mathrm{T}}=\mathrm{DSM}\right.$ $\left.20174^{\mathrm{T}}\right)$.

\section{Description of Lactobacillus plantarum subsp. argentoratensis subsp. nov.}

Lactobacillus plantarum subsp. argentoratensis (ar.gen.to.ra. ten'sis. L. masc. adj. argentoratensis of or pertaining to Argentorātus, the Roman name of the city of Strasbourg in Alsace, France, where the 14 strains were first collected and analysed).

Morphological, physiological and biochemical characteristics are the same as those of L. plantarum subsp. plantarum, with only a few exceptions: strains belonging to L. plantarum subsp. argentoratensis are not able to metabolize either melezitose or methyl $\alpha$-D-mannoside. Strains of this subspecies may be reliably differentiated from strains of $L$. plantarum subsp. plantarum by Southern hybridization with a pyr probe on BglI digestion of chromosomal DNA (Bringel et al., 1996, 2001), by multiplex species-specific PCR analysis (Torriani et al., 2001) and by recA gene sequencing, as reported in the present paper. When analysed by a specific multiplex-PCR approach (Torriani et al., 2001), DNA of strains belonging to this subspecies produce two 
amplification products, of 318 bp (specific for the species L. plantarum) and $120 \mathrm{bp}$ (specific for the L. plantarum subsp. argentoratensis subspecies).

The type strain is DKO $22^{\mathrm{T}}\left(=\mathrm{CIP} 108320^{\mathrm{T}}=\mathrm{DSM}\right.$ $\left.16365^{\mathrm{T}}\right)$.

\section{References}

Berthier, F. \& Ehrlich, S. D. (1998). Rapid species identification within two groups of closely related lactobacilli using PCR primers that target the 16S/23S rRNA spacer region. FEMS Microbiol Lett 161, 97-106.

Bringel, F., Curk, M. C. \& Hubert, J. C. (1996). Characterization of lactobacilli by Southern-type hybridization with a Lactobacillus plantarum pyrDFE probe. Int J Syst Bacteriol 46, 588-594.

Bringel, F., Quénée, P. \& Tailliez, P. (2001). Polyphasic investigation of the diversity within Lactobacillus plantarum related strains revealed two L. plantarum subgroups. Syst Appl Microbiol 24, 561-571.

Curk, M. C., Hubert, J. C. \& Bringel, F. (1996). Lactobacillus paraplantarum sp. nov., a new species related to Lactobacillus plantarum. Int J Syst Bacteriol 46, 595-598.

Dellaglio, F., Bottazzi, V. \& Vescovo, M. (1975). Deoxyribonucleic acid homology among Lactobacillus species of the subgenus Streptobacterium Orla-Jensen. Int J Syst Bacteriol 25, 160-172.

Dellaglio, F., Torriani, S. \& Felis, G. E. (2004). Reclassification of Lactobacillus cellobiosus Rogosa et al. 1953 as a later synonym of Lactobacillus fermentum Beijerinck 1901. Int J Syst Evol Microbiol 54, 809-812.

Freney, J., Kloos, W. E., Hajek, V., Webster, J. A., Bes, M., Brun, Y. \& Vernozy-Rozand, C. (1999). Recommended minimal standards for description of new staphylococcal species. Subcommittee on the taxonomy of staphylococci and streptococci of the International Committee on Systematic Bacteriology. Int J Syst Bacteriol 49, 489-502.

Hammes, W. P. \& Hertel, C. (2003). The genera Lactobacillus and Carnobacterium. In The Prokaryotes: an Evolving Electronic Resource for the Microbiological Community, 3rd edn, release 3.15, 15 December 2003. Edited by M. Dworkin et al. New York: SpringerVerlag. http:/link.springer-ny.com/link/service/books/10125/

Hammes, W. P. \& Vogel, R. F. (1995). The genus Lactobacillus. In The Genera of Lactic Acid Bacteria, pp. 19-54. Edited by B. J. B. Wood \& W. H. Holzapfel. Glasgow: Blackie Academic \& Professional.

Kleerebezem, M., Boekhorst, J., van Kranenburg, R. \& 17 other authors (2003). Complete genome sequence of Lactobacillus plantarum WCFS1. Proc Natl Acad Sci U S A 100, 1990-1995.

Kumar, S., Tamura, K., Jakobsen, I.-B. \& Nei, M. (2001). MEGA2: molecular evolutionary genetics analysis software. Bioinformatics $\mathbf{1 7}$, 1244-1245.

Lapage, S. P., Sneath, P. H. A., Lessel, E. F., Skerman, V. B. D., Seeliger, H. P. R. \& Clark, W. A. (editors) (1992). International Code of Nomenclature of Bacteria (1990 Revision). Bacteriological Code. Washington, DC: American Society for Microbiology.

Marmur, J. (1961). A procedure for the isolation of DNA from microorganisms. J Mol Biol 3, 208-218.

Sharpe, M. E. (1979). Identification of lactic acid bacteria. In Identification Methods for Microbiologists (Technical Series 14), pp. 233-259. Edited by F. A. Skinner \& D. W. Lovelock. London: Academic Press.

Thompson, J. D., Gibson, T. J., Plewniak, F., Jeanmougin, F. \& Higgins, D. G. (1997). The CLUSTAL_X Windows interface: flexible strategies for multiple sequence alignment aided by quality analysis tools. Nucleic Acids Res 25, 4876-4882.

Torriani, S., Felis, G. E. \& Dellaglio, F. (2001). Differentiation of Lactobacillus plantarum, L. pentosus, and L. paraplantarum by $r e c A$ gene sequence analysis and multiplex PCR assay with recA gene-derived primers. Appl Environ Microbiol 67, 3450-3454.

Vescovo, M., Torriani, S., Dellaglio, F. \& Bottazzi, V. (1993). Basic characteristics, ecology and application of Lactobacillus plantarum: a review. Ann Microbiol Enzymol 43, 261-284.

Zanoni, P., Farrow, J. A. E., Phillips, B. A. \& Collins, M. D. (1987). Lactobacillus pentosus (Fred, Peterson and Anderson) sp. nov., nom. rev. Int J Syst Bacteriol 37, 339-341. 